\title{
Relative Fat Mass, a new tool for measuring obesity, could predict the complications of type 2 diabetes
}

Isabelle Jambart ${ }^{*}$, Ghassan Sleilaty ${ }^{2}$, Sélim Jambart ${ }^{3}$, Rita Medlej ${ }^{3}$, Georges Halaby ${ }^{3}$, Chawki Atallah ${ }^{3}$, Marie-Hélène Gannagé-Yared ${ }^{3}$ Georges Hajje ${ }^{3}$

${ }^{1}$ Resident at Hôtel-Dieu de France hospital, Faculty of Medicine, Saint-Joseph University, Beirut, Lebanon.

${ }^{2}$ Clinical Research Center at Hôtel-Dieu de France Hospital, Faculty of Medicine, Saint-Joseph University, Beirut, Lebanon.

${ }^{3}$ Department of Endocrinology at Hôtel-Dieu de France hospital, Faculty of Medicine, Saint-Joseph University, Beirut, Lebanon.

*Corresponding author: Isabelle Jambart, Resident at Hôtel-Dieu de France hospital, Faculty of Medicine, Saint-Joseph University, Beirut, Lebanon.

Received Date: April 28, 2021; Accepted Date: May 25, 2021; Published Date: May $27,2021$.

Citation: I Jambart, G Sleilaty, S Jambart, R Medlej, G Halaby, et al. (2021) Relative Fat Mass, a new tool for measuring obesity, could predict the complications of type 2 diabetes. Journal of Endocrinology and Disorders. 5(3): Doi: 10.31579/2640-1045/074

Copyright: (c) 2021 Isabelle Jambart. This is an open-access article distributed under the terms of the Creative Commons Attribution License, which permits unrestricted use, distribution, and reproduction in any medium, provided the original author and source are credited.

\begin{abstract}
Aim/background: Obesity is a chronic disease contributing too many metabolic illnesses, in particular type 2 diabetes. The Relative Fat Mass (RFM) is a tool recently introduced for obesity which better predicts the level of visceral fat than the Body Mass Index (BMI). The aim of this study is to determine whether RFM is a better predictor of the cardiometabolic risk factors and the complications of type 2 diabetes than BMI.
\end{abstract}

Materials and methods: This is a cross sectional study. A list of information was collected from endocrinologists treating type 2 diabetic patients in a primary healthcare clinic and a tertiary hospital in Beirut. This list allowed us to evaluate the micro and macro vascular complications of type 2 diabetic patients, to assess their risk factors and to calculate their RFM and BMI.

Results: We analyzed the data of 359 patients. Higher RFM was associated with higher systolic blood pressure ( $\mathrm{p}<$ 0.05), and both RFM and BMI were significantly correlated to higher CRP, triglyceride levels and liver enzymes. However, the BMI was better associated with other cardiometabolic risk factors such as the total cholesterol $(\mathrm{p}=$ 0,003), LDL cholesterol $(\mathrm{p}=0,002)$ and HbA1c $(\mathrm{p}=0,01)$ than RFM. Both RFM and BMI were correlated with higher microalbuminuria $(\mathrm{p}<0.001)$ but unlike BMI, higher RFM was associated with higher creatinine level $(\mathrm{p}=0.317$ versus 0.047 respectively) and therefore better linked to diabetic nephropathy than BMI. More importantly, we observed an unprecedented result, associating RFM to diabetic neuropathy: a normal RFM excludes diabetic neuropathy with a high probability of $82.5 \%$. Furthermore, a RFM cutoff value of 30.76 in men and 43.31 in women showed an increased risk of developing diabetic neuropathy by 2.464 . No association was observed between RFM and diabetic retinopathy.

Conclusion: The RFM better predicts microvascular complications of diabetes than BMI except for retinopathy. It is also associated with a worse profile of metabolic syndrome. This study is unique in its discovery of the potential role of RFM as a tool which could rule out neuropathy in diabetic patients.

Keywords: relative fat mass; body mass index; cardio metabolic risk

\section{Aim/Background}

Obesity constitutes nowadays a real epidemic health problem [1]. It is defined as excess body fat and contributes greatly to the occurrence of several metabolic diseases, such as diabetes, hypertension, dyslipidaemia and many others which are responsible for cardiovascular complications [2]. It is also correlated to an increased incidence of complications in diabetic patients [3, 4]. This makes obesity a major public health issue, and in 1997, the World Health Organization defined it as a chronic disease rather than a simple aesthetic matter.
In clinical practice, the gold standard to measure obesity is the Body Mass Index (BMI). It is easy to calculate, reliable, and gives a better estimation of the body fat than weight alone. However, it has many limitations. It varies according to ethnicity $[5,6]$ and is not representative of the amount of visceral fat [7] which, by itself, constitutes an independent risk factor for morbidity [8-12]. BMI does not take into consideration the distribution of fat mass and fat free mass [13-16]. People with identical BMI can vary widely in percent body fat, which can lead to misclassification of bodyfat defined obesity. 
Another way of measuring obesity is waist circumference. It is simple, not related to height, and associates with visceral fat but it is also dependent on ethnicity [5, 17]. Evidence has shown that measuring waist circumference in clinical practice provides both independent and additive information to BMI for predicting morbidity and risk of death [18].

Anthropometric measures of body fat such as DEXA (Dual Energy X ray Absorptiometry), computerized tomography, MRI and biometric impedance evaluate visceral fat in a more precise manner than waist circumference [19-21] but are mostly dedicated to research because of their cost.

In 2018, a new tool, the Relative Fat Mass (RFM), was developed and many studies have shown that it is more accurate than BMI to estimate body fat percentage and more precise in the clinical diagnosis of obesity [22-26].

Since RFM is a very recently discovered tool, studies comparing the correlation of RFM and BMI to type 2 diabetes complications are rare.

The objective of this study is to determine whether RFM is a better predictor of the cardiometabolic risk factors and the complications of type 2 diabetes than BMI.

\section{Material and methods}

This is a cross-sectional study that took place in Lebanon from December 2018 to December 2019.

A series of information was collected from endocrinologists affiliated to a primary healthcare clinic and a tertiary hospital in Beirut, treating patients with type 2 diabetes (appendix). This information allowed us to evaluate the micro and macro vascular complications of these patients, to assess their risk factors and to calculate their RFM and BMI.

Inclusion criteria are type 2 diabetic patients treated by these endocrinologists. Patients with an $\mathrm{HbA} 1 \mathrm{c}<6.5 \%$ were excluded to make sure not to include patients taking antidiabetic medications for other purposes than diabetes.

The RFM formula includes height and waist circumference and is calculated as follows:

a - (20 x height / waist circumference $)$; a being 64 for men and 76 for women [7].

A statistical analysis was performed using the SPSS v16.0 computer program. The statistical tests used are the T-test, the ROC curve (Receiver Operating Characteristic), as well as the Chi-square test.

\section{Results}

359 patients were recruited, 221 men (61.6\%), and 138 women (38.4\%). The average age was 61 years old and the median BMI was $29.07 \mathrm{~kg} /$ $\mathrm{m} 2$. Microvascular complications were found in $44.6 \%$ of patients and macrovascular complications in $62.7 \%$. Characteristics of the patients are listed in table 1. The average RFM was 31.4 for men (Standard Deviation SD 3.32), and 44.1 for women (SD 3.93). RFM in men and women was normally distributed (Figure 1) and standardized in order to use a single value in the correlation calculations. The average for both genders was 36.27 (Figure 2).

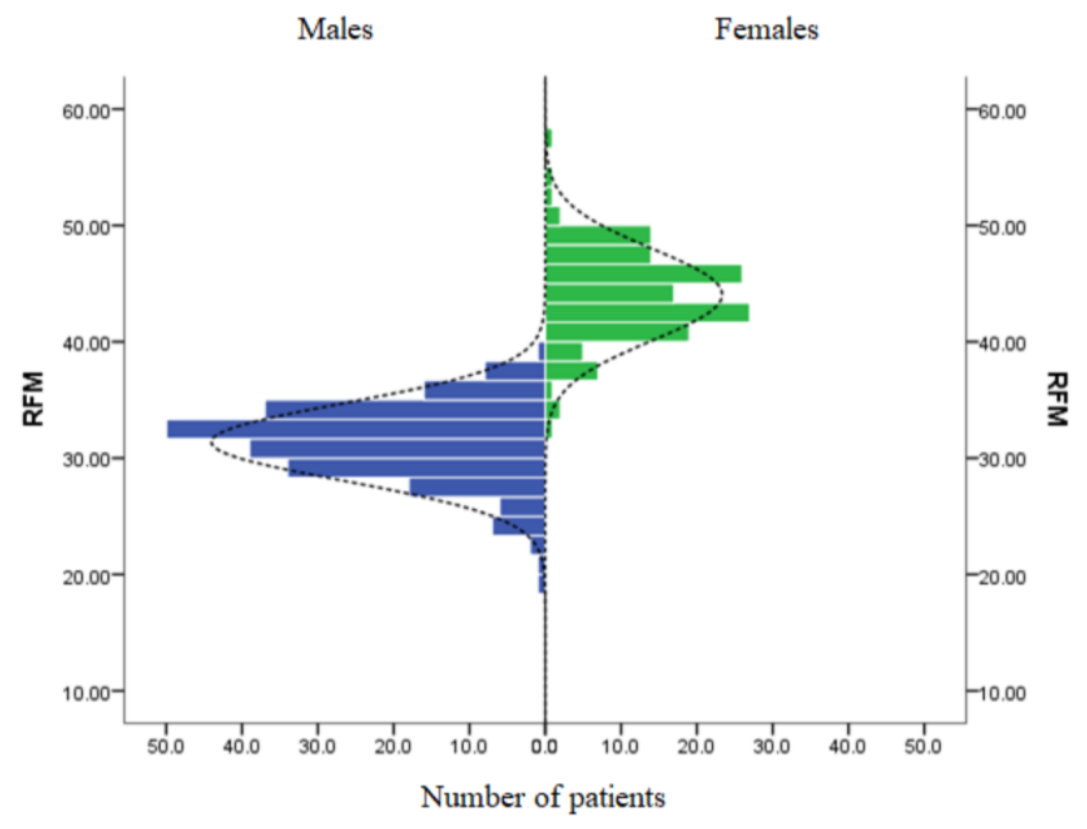

Figure 1: Distribution of RFM in men and women 


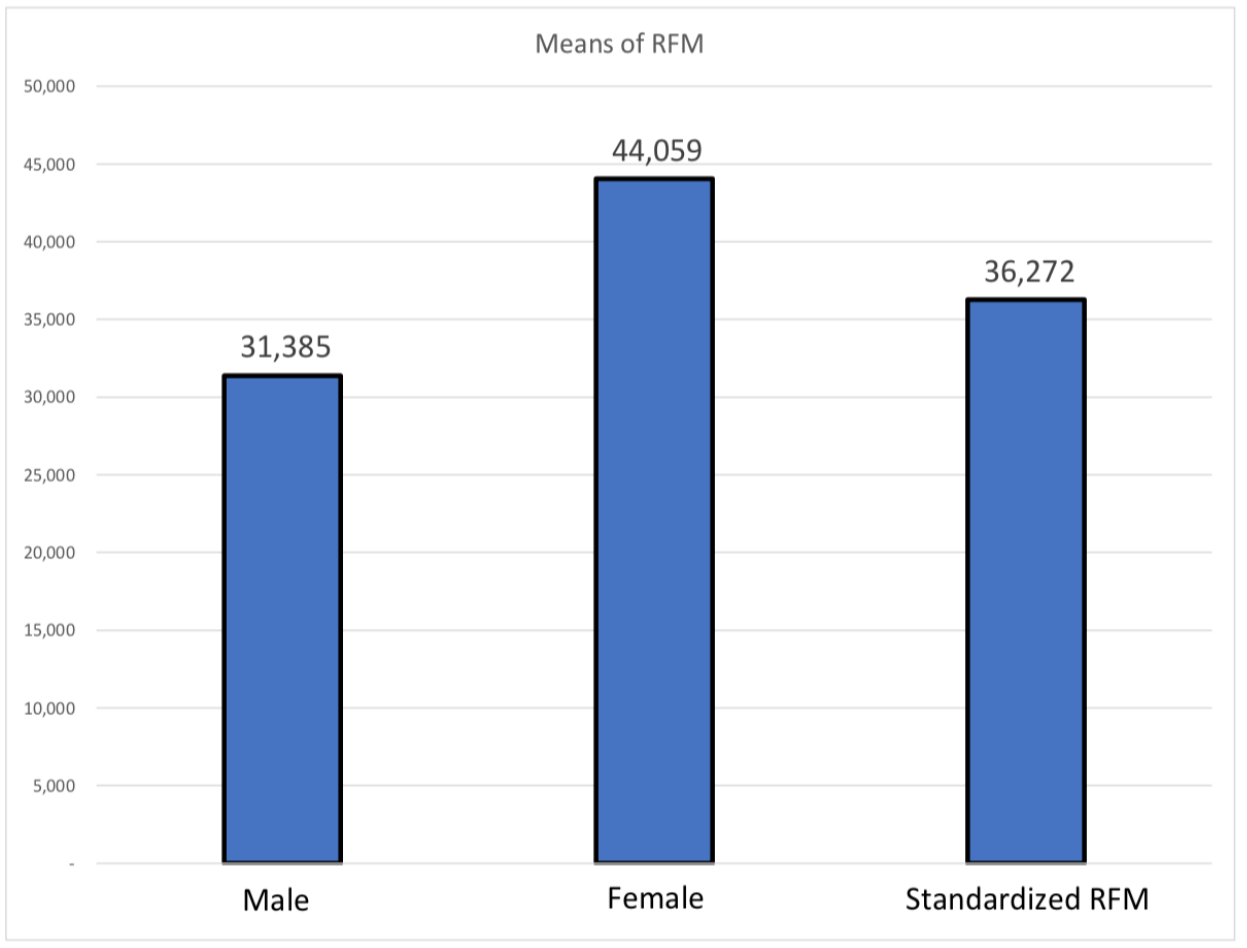

Figure 2: RFM averages for men and women, and calculated standardized RFM

Figure 2: RFM averages for men and women, and calculated standardized RFM

\begin{tabular}{|l|l|l|l|l|l|}
\hline & Median & $\begin{array}{l}\text { Percentile } \\
25\end{array}$ & $\begin{array}{l}\text { Percentile } \\
75\end{array}$ & $\begin{array}{l}\text { Number of } \\
\text { respondents }\end{array}$ & $\begin{array}{l}\text { Missing } \\
\text { data }\end{array}$ \\
\hline $\begin{array}{l}\text { Time since diagnosis } \\
\text { (years) }\end{array}$ & 10 & 4 & 16 & 260 & 99 \\
\hline HbA1C (\%) glucose & 141,0 & 121,5 & 181,5 & 352 & 4 \\
\hline $\begin{array}{l}\text { Blood }(\mathrm{mg} / \mathrm{dL}) \\
\text { CRP }\end{array}$ & 3,00 & 0,80 & 5,00 & 267 & 93 \\
\hline AST (U/L) & 22 & 16 & 34 & 343 & 12 \\
\hline ALT (U/L) & 20 & 16 & 26 & 266 & 93 \\
\hline GGT (U/L) & 25 & 17 & 40 & 325 & 35 \\
\hline $\begin{array}{l}\text { Alkaline Phosphatase } \\
\text { (U/L) }\end{array}$ & 62 & 50 & 80 & 229 & 130 \\
\hline $\begin{array}{l}\text { Total cholesterol } \\
\text { (mg/dL) }\end{array}$ & 165 & 142 & 197 & 353 & 6 \\
\hline $\begin{array}{l}\text { HDL cholesterol } \\
\text { (mg/dL) }\end{array}$ & 41 & 35 & 48 & 352 & 7 \\
\hline $\begin{array}{l}\text { LDL cholesterol } \\
\text { (mg/dL) }\end{array}$ & 92 & 70 & 125 & 352 & 7 \\
\hline Triglycerides (mg/dL) & 156 & 119 & 229 & 352 & 7 \\
\hline $\begin{array}{l}\text { Creatinine } \\
\text { (mg/dL) }\end{array}$ & 0,80 & 0,69 & 1,03 & 349 & 56 \\
\hline ACR level & 17,05 & 6,45 & 64,50 & 304 & 70 \\
\hline
\end{tabular}




\begin{tabular}{|c|c|c|c|c|}
\hline & & & & Missing data \\
\hline \multirow[t]{2}{*}{ Stent } & No & 303 & $86,8 \%$ & \multirow[t]{2}{*}{10} \\
\hline & Yes & 46 & $13,2 \%$ & \\
\hline \multirow[t]{2}{*}{ CABG } & No & 338 & $94,9 \%$ & \multirow[t]{2}{*}{3} \\
\hline & Yes & 18 & $5,1 \%$ & \\
\hline \multirow[t]{2}{*}{ Mesenteric ischemia } & No & 355 & $99,7 \%$ & \multirow[t]{2}{*}{3} \\
\hline & Yes & 1 & $0,3 \%$ & \\
\hline \multirow[t]{2}{*}{ Stroke } & No & 348 & $98,6 \%$ & \multirow[t]{2}{*}{6} \\
\hline & Yes & 5 & $1,4 \%$ & \\
\hline \multirow{2}{*}{$\begin{array}{ll}\text { Peripheral arterial } \\
\text { disease }\end{array}$} & No & 168 & $93,9 \%$ & \multirow[t]{2}{*}{179} \\
\hline & Yes & 11 & $6,1 \%$ & \\
\hline \multirow[t]{2}{*}{ Neuropathy } & No & 254 & $72,4 \%$ & \multirow[t]{2}{*}{7} \\
\hline & Yes & 97 & $27,6 \%$ & \\
\hline \multirow[t]{2}{*}{ Retinopathy } & No & 252 & $84,3 \%$ & \multirow[t]{2}{*}{60} \\
\hline & Yes & 47 & $15,7 \%$ & \\
\hline
\end{tabular}

Table 1b: Patient data collection

\begin{tabular}{|l|l|l|l|}
\hline & & Mean & SD \\
\hline RFM & 358 & 36,27 & 7,13 \\
\hline Standardized RFM & 358 & 0,00 & 1,00 \\
\hline
\end{tabular}

Table 1c: Patient data collection

M: male; F: female; BMI: body mass index; SBP: systolic blood pressure; DBP: diastolic blood pressure; ACR: albumin/creatinine ratio, CABG: coronary artery bypass graft; RFM: relative fat mass

For the cardiometabolic risk factors, higher RFM was associated with higher systolic blood pressure $(\mathrm{p}<0.05)$ whereas no correlation was found between RFM and diastolic blood pressure $(p=0.072)$. The RFM, as well as the BMI, were both significantly correlated to higher CRP and triglycerides levels and liver enzymes. Unlike RFM, BMI was significantly correlated to higher HbA1c (p-value of 0.010 vs 0.060 for RFM), total cholesterol (p-value of 0.003 vs 0.316 for RFM) and LDL-c (p-value 0.002 vs 0.179 for RFM). The HDL-c did not show any significant correlation to neither RFM nor BMI.

Regarding the macrovascular complications of diabetes, there was no statistically significant correlation between RFM and stenting, coronary artery bypass graft or peripheral arterial disease.
However, when assessing the microvascular complications of diabetes, we found an interesting correlation between RFM and diabetic nephropathy and neuropathy but not retinopathy. Indeed, unlike BMI, higher RFM was associated with higher creatinine level ( $p=0.317$ vs 0.047 respectively) and both RFM and BMI were correlated with higher microalbuminuria $(\mathrm{p}<0.001)$. Furthermore, the area under the curve of true positives (sensitivity) as a function of false positives (1-specificity) of RFM had a statistically significant correlation with diabetic neuropathy $(p=0.016)$, unlike that of BMI (Figure 3 and Table 2). RFM was found to have a negative predictive value of $82.5 \%$ for the diagnosis of diabetic neuropathy (Table 3). A RFM cutoff value of 30.76 in men and 43.31 in women showed an increased risk of developing diabetic neuropathy by 2.464 (CI 1.468 - 4.137). 


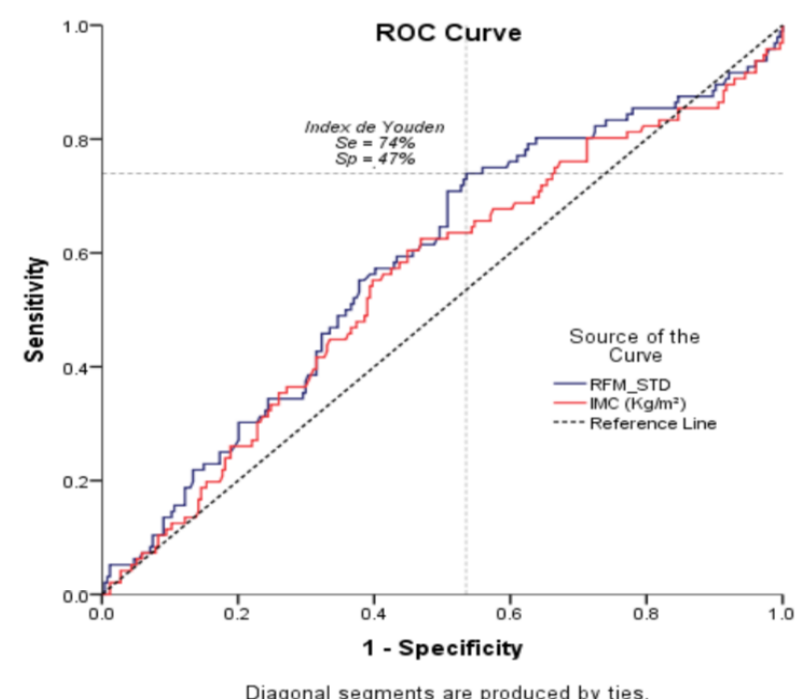

Figure 3: RFM and BMI True positives as a function of RFM and BMI false positives for diabetic neuropathy

Figure 3: True positives based on RFM and BMI false positives for diabetic neuropathy

\begin{tabular}{|l|l|}
\hline Variables & $\begin{array}{l}\text { Correlation with the area under the ROC curve of the RFM and } \\
\text { the BMI (kg / m2) (p-value) }\end{array}$ \\
\hline Diabetic neuropathy & $\begin{array}{l}\text { Standardized RFM : 0,016 } \\
\text { BMI : 0,125 }\end{array}$ \\
\hline Stent & $\begin{array}{l}\text { Standardized RFM : 0,204 } \\
\text { BMI : 0,544 }\end{array}$ \\
\hline CABG & $\begin{array}{l}\text { Standardized RFM : 0,155 } \\
\text { BMI : 0,761 }\end{array}$ \\
\hline $\begin{array}{l}\text { Mesenteric ischemia } \\
\text { (diagnosed with computed } \\
\text { tomographic angiography } \\
\text { without oral contrast) }\end{array}$ & $\begin{array}{l}\text { Standardized RFM : 0,339 } \\
\text { BMI : 0,626 }\end{array}$ \\
\hline Stroke & $\begin{array}{l}\text { Standardized RFM : 0,174 } \\
\text { BMI : 0,637 }\end{array}$ \\
\hline Peripheral artery disease & $\begin{array}{l}\text { Standardized RFM : 0,648 } \\
\text { BMI : 0,653 }\end{array}$ \\
\hline Diabetic retinopathy & $\begin{array}{l}\text { Standardized RFM : 0,253 } \\
\text { BMI : 0,311 }\end{array}$ \\
\hline
\end{tabular}

Table 2: Correlation of areas under the curve of standardized RFM and BMI, with the history of diabetic neuropathy, stent placement, aortocoronary bypass surgery, mesenteric ischemia, stroke, obliterating arterial disease of the limbs and diabetic retinopathy

CABG: coronary artery bypass graft

\begin{tabular}{|l|l|l|}
\hline & & Confidence interval (95\%) \\
\hline NPV & $82,5 \%$ & $75,7 \%-88,1 \%$ \\
\hline Specificity & $46,5 \%$ & $40,4 \%-52,6 \%$ \\
\hline PPV & $34,3 \%$ & $28,1 \%-40,9 \%$ \\
\hline Sensitivity & $74,0 \%$ & $64,6 \%-81,9 \%$ \\
\hline
\end{tabular}

Table 3: Negative predictive value, specificity, positive predictive value and sensitivity of RFM for the diagnosis of diabetic neuropathy NPV: negative predictive value, PPV: positive predictive value 


\section{Discussion}

This is, to our knowledge, the first study on RFM performed on a population of diabetic patients assessing the correlation between RFM as an obesity marker and diabetic complications.

Nowadays, BMI is the most commonly and widely used obesity marker. Other markers such as waist circumference are also used by physicians. Numerous recent studies [22-26] proved the validity of RFM as a tool for measuring obesity or visceral fat. RFM was superior to BMI in diagnostic accuracy for obesity among men, women, and across ethnic groups [27]. Compared with abnormal BMI, abnormal RFM better predicted obesity among men and women using dual energy X-ray absorptiometry (DXA) as the gold standard (19); it was also found to be superior to BMI as a predictor of diabetes. According to Woolcott and Bergamn, the threshold of RFM beyond which a patient is considered obese and therefore at higher risk of mortality was set at 40 in women and 30 in men [26]. In our diabetic population, $68.6 \%$ of men and $87.9 \%$ of women have an RFM > 30 and $>40$ respectively and thus are considered obese. When using the BMI with a cut-off of 30 , only $44.4 \%$ of men and $44.3 \%$ of women are considered obese. This reflects the increasing prevalence of obesity among diabetic patients in our population using the RFM tool and therefore their increased risk of morbidity.

Our study emphasizes the correlation of RFM to higher triglycerides level as it was demonstrated by Leiba et al in their study showing that RFM is a better predictor of dyslipidemia and metabolic syndrome than Body Mass Index [29]. However, we found that BMI was better than RFM in its correlation to total cholesterol and LDL cholesterol. Furthermore, as shown by Kobo et al [22], RFM as the obesity criterion of metabolic syndrome encompasses a larger proportion of the population as suffering from metabolic syndrome. Indeed, our study better correlates RFM to some of the components of the metabolic syndrome: systolic blood pressure, triglycerides and obesity.

Machado et al [29] compared the roles of RFM and BMI as predictors of the severity of non-alcoholic fatty liver disease. They did not observe any significant difference between both tools [30]. This is in line with the results of our study which did not reveal any significant difference between the correlations of RFM and BMI with the markers of liver function: AST, ALT, GGT, alkaline phosphatase.

This study is the first to find an interesting correlation between RFM and diabetic nephropathy and neuropathy.

The high negative predictive value implies that RFM would be a good screening tool for diabetic neuropathy, since a normal RFM could eliminate the presence of neuropathy with a probability of $82.5 \%$. In addition, a high RFM (> $30.76 \%$ in men and $43.31 \%$ in women), implies a risk of neuropathy multiplied by 2.464 . However, although the risk more than doubled, that probability/risk still does not exceed $34.3 \%$, which is not enough to make RFM a diagnostic tool for neuropathy. It would be interesting to confirm these findings with another study in a new population of diabetics. This study would verify whether patients with normal RFM indeed do not have diabetic neuropathy. It would also be noteworthy to identify the reasons why RFM is correlated to diabetic neuropathy and nephropathy only, and not to diabetic retinopathy and other macrovascular complications.

Our study has some limitations. It is a cross-sectional study, which reduces its power. In addition, the population comprises diabetic patients treated by endocrinologists affiliated to two health care centres. This means that we cannot generalize the results to the rest of the Lebanese population, or to the Lebanese diabetic patients. This study only includes diabetic patients with an HbA1C greater than or equal to 6.5. The results are therefore not applicable to patients with pre-diabetes. Finally, the majority of patients with type 2 diabetes who visit their endocrinologist are already being treated for their diabetes, which means that those of them who have an HbA1C below $6.5 \%$ thanks to their treatment were eliminated from the study.

\section{Conclusion}

The RFM is a very promising new clinical tool, which has been proven to be superior to BMI in predicting the percentage of body fat mass associated with DEXA scan results. It is also associated with a worse profile of metabolic syndrome. This study is unique in its discovery of a relationship between RFM and diabetic neuropathy and nephropathy, and the potential role of RFM as a factor that might rule out neuropathy in diabetic patients. However, further studies are needed to validate this finding.

\section{Annex}

List of information collected from patients:

- Age, sex, weight, height, waist circumference

- Date of onset of diabetes

- Blood pressure

- HbA1C and blood glucose

- Creatinine and micro-albuminuria (ACR)

- CRP

- Diabetic neuropathy (diagnosed by questioning patients and carrying out a targeted physical examination: tuning fork, thread)

- Diabetic ophthalmopathy (Normal or pathological fundus)

- Complete liver panel: AST, ALT, GGT, alkaline phosphatases

- Lipid profile: total cholesterol, HDL cholesterol, LDL cholesterol, triglycerides

- Cardiovascular history: stent, coronary artery bypass graft, mesenteric ischemia, stroke, peripheral artery disease.

\section{Abbreviations:}

ACR: albumin/creatinine ratio

BMI: body mass index

CABG: coronary artery bypass graft

DBP: diastolic blood pressure

F: female

M: male

RFM: relative fat mass

SBP: systolic blood pressure

Declarations:

Ethics approval: approved by the ethics committee of Hôtel-Dieu de France Hospital and the Faculty of Medicine of Saint Joseph University.

Consent for Publication: not applicable 
Availability of Data and material: The datasets used and/or analyzed during the current study available from the corresponding author on reasonable request.

Competing interests: the authors declare that they have no competing interests.

\section{Funding: None}

Authors' contribution: GH and IJ wrote the manuscript and established the research plan. DA, GHajje, GHalabi, MHGY, RM and SJ helped in the collection of the data required from each patient. GS analyzed and interpreted the data collected. All authors read and approved the final manuscript.

\section{Acknowledgements: Not applicable}

\section{References:}

1. Collaborators TG (2015) O. Health Effects of Overweight and Obesity in 195 Countries over 25 Years

2. NCD Risk Factor Collaboration (NCD-RisC). (2016) Trends in adult body-mass index in 200 countries from 1975 to 2014: a pooled analysis of 1698 population-based measurement studies with 19.2 million participants. Lancet;

3. Bray GA. (2007) The battle of the bulge: a history of obesity research. Pittsburgh, Penn.: Dorrance Pub.

4. Dietz WH. (1998) Health Consequences of Obesity in Youth: Childhood Predictors of Adult Disease. Pediatrics. 101(Supplement 2):518-525.

5. Deurenberg P, Yap M, van Staveren WA. (1998) Body mass index and percent body fat: a meta analysis among different ethnic groups. Int J Obes Relat Metab Disord. 22(12):11641171.

6. Razak Fahad, Anand Sonia S., Shannon Harry, Vuksan Vladimir, Davis Bonnie, Jacobs Ruby, et al. (2007) Defining Obesity Cut Points in a Multiethnic Population. Circulation. 115(16):2111-2118.

7. Cedars-Sinai Staff. (2018) Building a Better Body Measurement: Relative Fat Mass. Science + Innovation.

8. Janssen I, Katzmarzyk PT, Ross R. (2004) Waist circumference and not body mass index explains obesity-related health risk. Am J Clin Nutr. 79(3):379-384.

9. Simpson JA, MacInnis RJ, Peeters A, Hopper JL, Giles GG, English DR. (2007) A Comparison of Adiposity Measures as Predictors of All-cause Mortality: The Melbourne Collaborative Cohort Study. Obesity. 5(4):994-1003.

10. Koster A, Leitzmann MF, Schatzkin A, Mouw T, Adams KF, van Eijk JT, Hollenbeck AR, Harris TB. (2008) Waist circumference and mortality. American Journal of Epidemiology.

11. Jacobs EJ, Newton CC, Wang Y, Patel AV, McCullough ML, Campbell PT, Thun MJ, Gapstur SM. (2010) Waist circumference and all-cause mortality in a large US cohort. Archives of Internal Medicine.

12. Tsai AG, Wadden TA. (2013) In the clinic: obesity. Annals of Internal Medicine.

13. Kok P, Seidell JC, Meinders AE. (2004) [The value and limitations of the body mass index (BMI) in the assessment of the health risks of overweight and obesity]. Ned Tijdschr Geneeskd. 148(48):2379-2382.

14. Nuttall FQ. (2015) Body Mass Index. Nutr Today. 50(3):117128.
15. Padwal R, Leslie WD, Lix LM, Majumdar SR. (2016) Relationship Among Body Fat Percentage, Body Mass Index, and All-Cause Mortality: A Cohort Study. Ann Intern Med. 164(8):532-5341.

16. Accuracy of Body Mass Index to Diagnose Obesity In the US Adult Population (2021).

17. Gallagher D, Heymsfield SB, Heo M, Jebb SA, Murgatroyd PR, Sakamoto Y. (2000) Healthy percentage body fat ranges: an approach for developing guidelines based on body mass index. The American Journal of Clinical Nutrition.

18. Ross R, Neeland IJ, Yamashita S, Shai I, Seidell J, Magni P, et al. (2020) Waist circumference as a vital sign in clinical practice: a Consensus Statement from the IAS and ICCR Working Group on Visceral Obesity. Nat Rev Endocrinol. 16(3):177-189.

19. Validation of DXA Body Composition Estimates in Obese Men and Women - LaForgia - 2009 - Obesity - Wiley Online Library [Internet]. (2019)

20. Shen W, Punyanitya M, Wang Z, Gallagher D, St-Onge M-P, Albu J, et al. (2004) Visceral adipose tissue: relations between single-slice areas and total volume. Am J Clin Nutr. 80(2):271278.

21. Machann J, Thamer C, Stefan N, Schwenzer NF, Kantartzis K, Häring H-U, et al. (2010) Follow-up Whole-Body Assessment of Adipose Tissue Compartments during a Lifestyle Intervention in a Large Cohort at Increased Risk for Type 2 Diabetes. Radiology. 257(2):353-363.

22. Orison O. Woolcott \& Richard N. Bergman. Relative fat mass (RFM) as a new estimator of whole-body fat percentage - A cross-sectional study in American adult individuals.

23. Kobo O, Leiba R, Avizohar O, Karban A. (2019) Relative fat mass (RFM) as abdominal obesity criterion for metabolic syndrome. European Journal of Internal Medicine. 63:e9-11.

24. Woolcott OO, Bergman RN. (2019) Relative Fat Mass as an estimator of whole-body fat percentage among children and adolescents: A cross-sectional study using NHANES. Sci Rep. $9(1): 1-14$.

25. Usefulness of relative fat mass in estimating body adiposity in Korean adult population.( 2020 ).

26. Guzmán-León AE, Velarde AG, Vidal-Salas M, Urquijo-Ruiz LG, Caraveo-Gutiérrez LA, Valencia ME. (2019) External validation of the relative fat mass (RFM) index in adults from north-west Mexico using different reference methods. PLOS ONE.14(12):e0226767.

27. Woolcott OO, Bergman RN. (2018) Relative fat mass (RFM) as a new estimator of whole-body fat percentage - A crosssectional study in American adult individuals. Sci Rep. 8(1):111.

28. pubmeddev, RN WO and B. (2020) Defining cutoffs to diagnose obesity using the relative fat mass (RFM): Association with mortality in NHANES 1999-2014.

29. Ofer Kobo Ronit Leiba, Ophir Avizohar and Amir Karban. (2019) Relative fat mass is a better predictor of dyslipidemia and metabolic syndrome than body mass index. Cardiovascular Endocrinology \& Metabolism.

30. Machado MV, Policarpo S, Coutinho J, Carvalhana S, Leitão J, Carvalho A, et al. (2019) What Is the Role of the New Index Relative Fat Mass (RFM) in the Assessment of Nonalcoholic Fatty Liver Disease (NAFLD)? 
This work is licensed under Creative Commons Attribution 4.0 License

To Submit Your Article Click Here: Submit Manuscript

DOI: $10.31579 / 2692-9759 / 074$
Ready to submit your research? Choose Auctores and benefit from:

* fast, convenient online submission

* rigorous peer review by experienced research in your field

* rapid publication on acceptance

* authors retain copyrights

* unique DOI for all articles

* immediate, unrestricted online access

At Auctores, research is always in progress.

Learn more www.auctoresonline.org/journals/endocrinology-anddisorders- 